\title{
Pre-folding magnetization reconfirmed for the Late Ordovician-Early Silurian Dunn Point volcanics, Nova Scotia
}

\author{
REX J.E. JOHNSON and ROB VAN DER VOO \\ Department of Geological Sciences, University of Michigan, Ann Arbor, MI 48109-1063 (U.S.A.)
}

(Received April 25, 1989; accepted August 25, 1989)

\begin{abstract}
Johnson, R.J.E. and Van der Voo, R., 1990. Pre-folding magnetization reconfirmed for the Late Ordovician-Early Silurian Dunn Point volcanics, Nova Scotia. Tectonophysics, 178: 193-205.

Paleomagnetic results have been obtained for three new sites in steeply inclined subareal volcanic flows of the Dunn Point Formation from the Avalon terrane of Nova Scotia. Demagnetization analysis reveals a characteristic magnetization, carried by hematite, which is similar to that reported in previous studies of this unit. A new and improved fold test for the characteristic component, combining paleomagnetic and structural data from the present study with paleomagnetic data for vertically dipping flows (and laterites) studied previously by the authors, is significantly positive. The new fold test reconfirms the prefolding age of the characteristic component. A primary age of magnetization is inferred, based on field evidence for early oxidation of the flows. The overall mean direction for the characteristic component of $D=344^{\circ}, I=-60^{\circ}, k=68.6, \alpha_{95}=4.1^{\circ}$ (paleopole at $2^{\circ} \mathrm{N}, 130^{\circ} \mathrm{E}$ ) corresponds to a Late Ordovician-earliest Silurian paleolatitude for Avalon of $41^{\circ} \mathrm{S}$. The latter is much higher than that predicted for the area on the basis of the cratonic North America apparent polar wander path, implying a substantial post-Ordovician displacement $(\geqslant 1700 \mathrm{~km}$ ) of Avalon with respect to the craton. The Dunn Point result supports previous paleogeographic reconstructions that show Avalon together with the continental blocks of Hercynian Europe and northwestern Gondwana.
\end{abstract}

\section{Introduction}

The latest Ordovician-earliest Silurian Dunn Point Formation is part of the Avalon terrane in the northern Appalachians. Recently published Late Precambrian and Early Paleozoic paleomagnetic results from this terrane (Weisse et al., 1985; Johnson and Van der Voo, 1985; 1986; Fang et al., 1986) show that it formerly occupied intermediate to high southern paleolatitudes, which contrast with the near equatorial position determined for North America for the same interval (e.g., Watts et al., 1980; Lynnes and Van der Voo, 1984; Dunn and Elmore, 1985). These results thus confirm the displaced nature of the Avalon terrane relative to North America. On the other hand, the Early Paleozoic paleolatitudes occupied by Avalon are similar to those found for Gondwana and the continental blocks of Hercynian Europe, and on the basis of their geologic and faunal similarities (e.g., Wilson, 1966; Rast and Skehan, 1983), it appears likely that Avalon was together with these blocks. Many authors have argued that such a configuration probably persisted at least through Ordovician time (e.g., Cocks and Fortey, 1982; Van der Voo, 1988). Previous paleomagnetic investigations of the Dunn Point Formation were undertaken in order to determine the position of Avalon relative to the major Atlantic-bordering continents in the Late Ordovician-earliest Silurian.

Two paleomagnetic studies of the Dunn Point Formation have been published (Van der Voo and Johnson, 1985; Seguin et al., 1987). While similar 
magnetic in-situ directions were reported, there are several significant discrepancies related to the interpretation of the number of magnetization components present in the volcanics, as well as their ages and tectonic setting. Probably the most important of these differences involves the age of

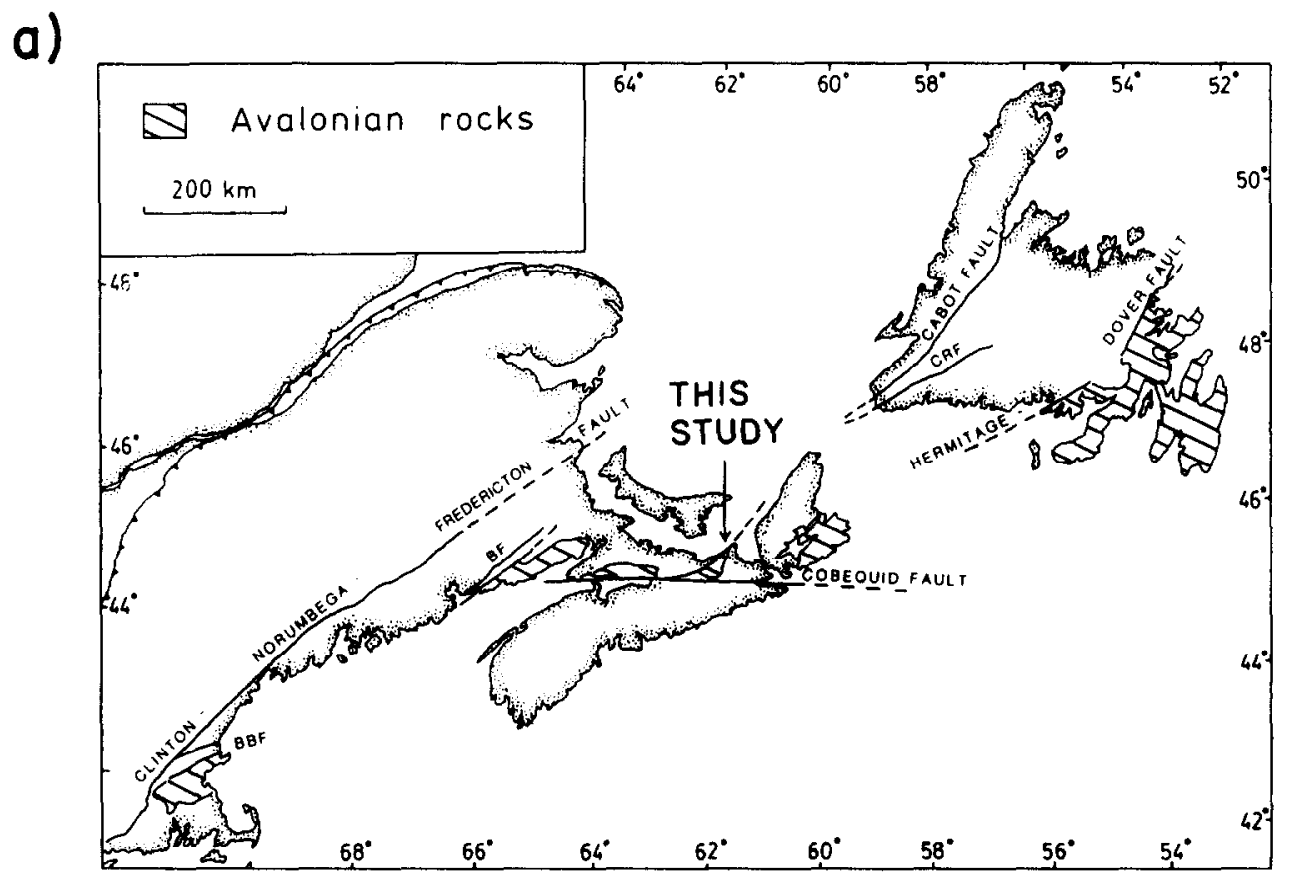

b)

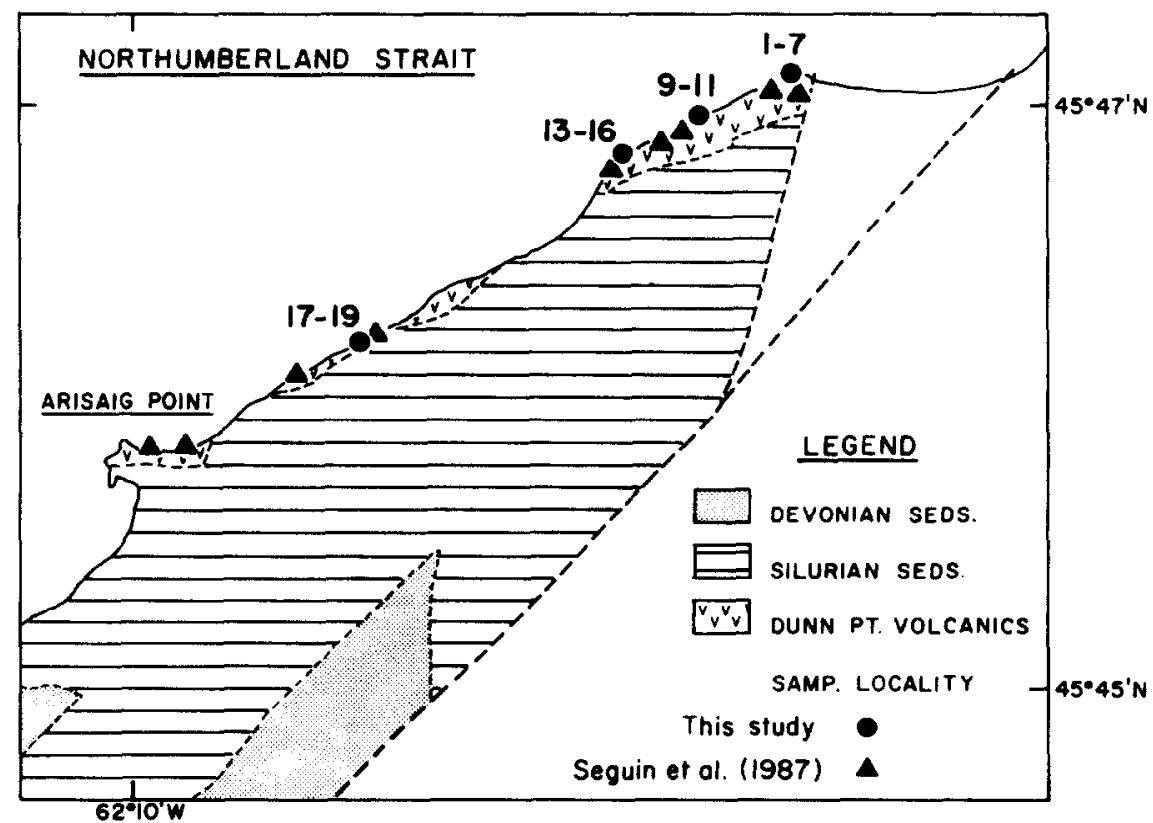

Fig. 1. (a) Map showing the location of the study area in the Avalon terrane of Nova Scotia, and (b) generalized geologic map of the Arisaig region showing the paleomagnetic sampling localities in the Dunn Point volcanics. The circles denote our sampling localities and the individual sites sampled at each locality are numbered; the triangles mark the sites of Seguin et al. (1987). 
the observed high-temperature characteristic magnetization: Van der Voo and Johnson (1985) report a positive fold test and argue for a primary magnetization, whereas Seguin et al. (1987) obscrve the fold test to be inconclusive, arguing for a post-folding (Jurassic?) age of the magnetization. In the present paper we document new paleomagnetic and structural data from the Dunn Point Formation and describe the results of a new fold test that better constrains the age of the stable high blocking temperature magnetization in the volcanics. The previous interpretations by both groups of workers are examined in the light of these new data.

\section{Geological setting}

The Dunn Point Formation occurs along the Northumberland coast of mainland Nova Scotia near Arisaig (Fig. 1). The stratified rocks of the Arisaig region, including the Dunn Point Formation, have been described by Boucot et al. (1974), Benson (1974), Keppie et al. (1978), and Pickerill and Hurst (1983). The Dunn Point is a bimodal sequence of volcanics some $200 \mathrm{~m}$ thick, consisting of predominantly vesicular basalt flows but including variable amounts of interlayered rhyolites in the upper part of the formation. The individual flow units are 1 to $5 \mathrm{~m}$ thick. The Dunn Point is overlain by felsic volcanics of the McGillivray Brook Formation (130 m thick) which are in turn overlain conformably, or with slight angular unconformity, by Lower Silurian fossiliferous marine strata of the Arisaig Group (e.g., Pickerill and Hurst, 1983). A whole-rock $\mathrm{Rb}-\mathrm{Sr}$ age of $434 \pm 15$ Ma for the Dunn Point and McGillivray Brook formations (Keppie et al., 1978) places them roughly at the boundary between the Ordovician and Silurian periods, consistent with the paleontological evidence for the age of the overlying sediments.

The tops of nearly all of the flows in the Dunn Point Formation are oxidized; moreover, red soil profiles interpreted as laterites by Boucot et al. (1974) and Keppie et al. (1978), are occasionally interstratified with the volcanics. The interiors of the basalt flows also show hematite staining but in all cases the tops of flows are more extensively oxidized. This evidence suggests that the volcanics were deposited subareally and that individual flows were probably oxidized a short time after their formation. Incorporation of laterite xenoliths within less oxidized material at the base of some flows reinforces the interpretation that oxidation and formation of these red soils were very early (e.g., Keppie et al., 1978). These observations are important for the interpretation of the paleomagnetic results for the volcanics, because they suggest that the formation of the magnetically very stable mineral hematite was essentially coeval with the formation of the volcanics.

The Dunn Point strata and the overlying Arisaig Group were tilted together in post-Early Devonian time in an episode of deformation that has been correlated with the Acadian orogeny in the northern Appalachians (Boucot et al., 1974). The Dunn Point volcanics along the Arisaig coast all have east-northeasterly strikes and very steep to vertical dips. The vesicular tops of the flows indicate that they young consistently toward the south-southeast and, thus, some sections of the volcanics are slightly overturned (e.g., Van der Voo and Johnson, 1985).

\section{Previous paleomagnetic studies}

The earlier study of the Dunn Point Formation by Van der Voo and Johnson (1985) was based on results obtained for basalts and laterites from three localities (16 sites) in the northernmost outcrop belt shown in Fig. 1. Initial sampling was concentrated in that belt for reasons of accessibility; moreover, it provides some of the best exposures of the volcanics in the entire study area. Although the volcanic strata in the northern belt all have very similar dips, a fold test was available as the result of a small but significant variation in strike between different parts of the belt.

Nearly all of the basalt and laterites samples examined by Van der Voo and Johnson (1985) revealed a characteristic component of magnetization having unblocking temperatures between $550^{\circ}$ and $675^{\circ} \mathrm{C}$, which was therefore inferred to be carried by hematite. An additional soft present-day field overprint magnetization was found in approximately $20 \%$ of the samples, although not 
shown in detail in the earlier study. The in situ site mean directions for the high temperature components revealed a non-Fisherian distribution, in which the directions from sites having different bedding strikes grouped separately. Simple correction for tilt by rotation about the strike direction, on the other hand, yielded a Fisherian distribution with a much lower dispersion $\left(k_{2} / k_{1}=2.7\right.$ based on $N=15$ sites; 96 samples), thus indicating a positive fold test significant at the $99 \%$ confidence level (McElhinny, 1964) and a pre-folding age for the characteristic magnetization. Based on the field evidence for the (early) formation of hematite in the Dunn Point, the high blocking temperature magnetization carried by this mineral was inferred to be a Chemical Remanent Magnetization (CRM) acquired during oxidation of the volcanics shortly after their deposition in Late Ordovician/Early Silurian time. The overall mean direction for the characteristic magnetization in the Dunn Point, after correction for tilt $\left(D=335^{\circ}, I=-61^{\circ}, \alpha_{95}\right.$ $=5.1^{\circ}$ ), indicated a paleolatitude for Avalon of $42^{\circ} \mathrm{S}$, which is different from the sub-equatorial paleolatitude (approximately $20^{\circ} \mathrm{S}$ ) predicted for the Appalachian margin of North America in the Late Ordovician from cratonic poles. Thus, these authors inferred that Avalon was separate from North America at that time.

For their study, Seguin et al. (1987) obtained samples of the Dunn Point Formation from all three outcrop belts shown in Fig. 1. They likewise found a stable high blocking temperature component carried by hematite ( $A$ component of Seguin et al., 1987) in the majority of their samples, and the directions given for this component, both in situ and tilt corrected, are similar to those reported by Van der Voo and Johnson (1987). Yet the fold test, based on their somewhat broader distribution of sampling sites, was not significant. Moreover, these authors reported directions for two additional components of magnetization ( $B$ and $C$ components) that were not observed by Van der Voo and Johnson (1985). These latter components were apparently present as overprints in some samples and as single components in others. The fold tests for the $B$ and $C$ components were similarly inconclusive. All three components found in this second study were interpreted by the authors as secondary, post-folding magnetizations (Seguin et al., 1987). The $B$ component was considered to be an overprint of Devonian age, probably acquired during the Acadian orogeny, while the $A$ component was inferred to be a CRM of possibly Jurassic age. The origin of the $C$ component was not discussed. Seguin et al. (1987) therefore concluded that none of the paleomagnetic directions recorded in the Dunn Point strata could be used to constrain the position of the Avalon terrane in Late Ordovician/Early Silurian time.

Clearly there are major differences between the two previous studies of the Dunn Point, in terms of the results obtained and their interpretation. Seguin et al. (1987) did not discuss the reasons for these differences in detail, noting only that "clearly they are of a lithologic or structural nature" (Seguin et al., 1987, p. 375). Possible explanations for the dissimilar results are investigated further in the present study in which new structural and paleomagnetic data that bear on the fold test for the high temperature component are reported.

\section{Methods and new results}

One of the purposes of the present study is to report new paleomagnetic results for sites in tilted flows from the middle outcrop belt of the Dunn Point (Fig. 1), which can be combined with data from our previous study to yield a more definitive fold test for the high temperature component. In particular, the data from the new sites allow us to test for the presence of undetected structural complexities (e.g., originally non-horizontal flows, multiple episodes of deformation) that could conceivably cause the fold test for the high temperature component to be inconclusive.

In addition, we report a large number of paleohorizontal measurements from the new locality as well as from our previous localities in the northern outcrop belt. The latter were obtained to test and refine, if necessary, the paleohorizontal estimates we used in our initial study based on relatively few measurements. Because in some cases the paleohorizontal orientations reported by Seguin et al., (1987) for nearby sampling sites in the northern outcrop belt were different from ours, the new measurements were carried out to provide 
a check on the accuracy, and precision, of the paleohorizontal orientations used in the fold test.

Because the procedures used for the sampling and paleohorizontal measurements are important in determining the overall accuracy of the results, these methods are briefly reviewed first.

\section{Sampling methods}

One of the most important criteria for selecting sampling sites in any study of stratified volcanics is that the orientation of paleohorizontal must be accurately determined. Since interlayered sediments suitable for bedding measurements are rarely present in the Dunn Point Formation, paleohorizontal was estimated throughout the study area from the contacts between the volcanic flows, which were sometimes irregular. A major concern, particularly regarding the smaller outcrops, was that flow contacts locally oblique to paleohorizontal might not be recognized as such. However, this problem was minimized in large continuous exposures of the volcanics where sightings along the contacts could be made, and especially where measurements of the contacts between several successive flows could be compared and averaged. In practice, therefore, only those exposures were sampled where at least $25 \mathrm{~m}$ of section, both laterally and vertically (stratigraphically), were exposed.

One new section in the volcanics which met this criterion, and where the volcanics were significantly inclined (but not vertical), was found in the middle outcrop belt shown in Fig. 1. Paleomagnetic samples were obtained from three separate flows within this section; as in our previous study, each flow is considered to be a separate site (sites DP17-19; Fig. 1), and the bottom, middle and top of each flow was sampled. According to the location map of Seguin et al. (1987), their site D4 is probably located in the same section. However, the exact location of their sites could not be determined from the map provided, nor in the field, since they collected exclusively oriented block samples.

Samples from each of the new sites were collected with a portable gas-powered core drill. In addition, a number of oriented hand samples were taken from the uppermost flow site (DP 19) which proved extremely difficult to drill. The sample orientations; as well as the "bedding" (paleohorizontal) measurements, were determined with a magnetic Brunton compass. In view of the the low Natural Remanent Magnetization (NRM) intensities in the volcanics (see below), local magnetic effects on the orientation measurements can be considered as insignificant.

\section{Paleohorizontal measurements}

All of our original sampling localities met or exceeded the minimum sampling criterion described above, so that the orientations of several flow contacts could be recorded over a fairly large area at each locality. The individual measurements made at these localities as well as the new locality are plotted in Fig. 2, and the means that were ultimately used to perform the tilt corrections are listed in Table 1.

\section{POLES TO BEDDING}
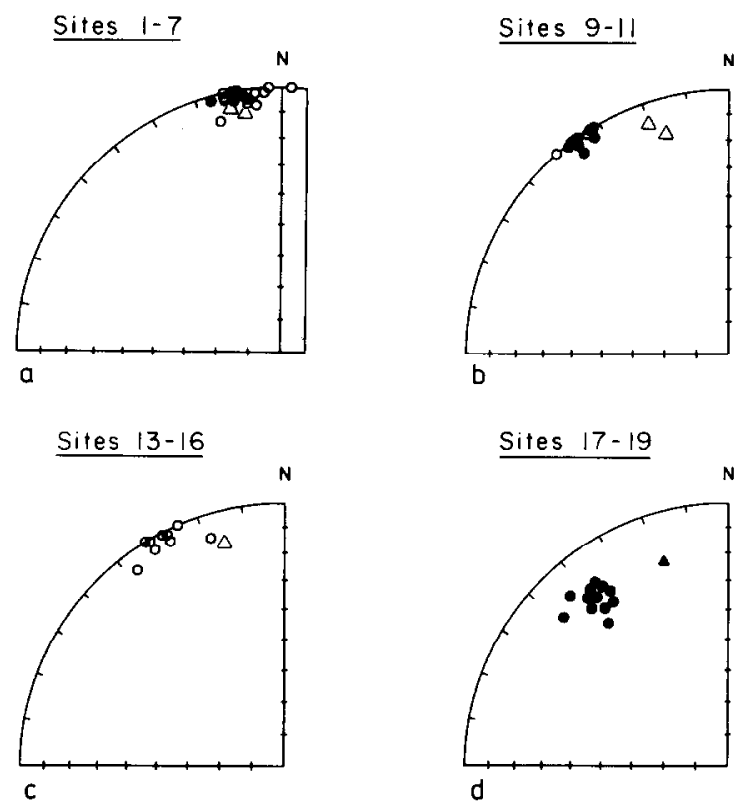

Fig. 2. Equal area plots of the downward normals to bedding (paleohorizontal) at each of four sampling localities in the Dunn Point volcanics. The circles denote our measurements; the triangles are the values reported by Seguin et al. (1987) for nearby sampling sites, as determined from their location map. The filled (open) symbols represent lower (upper) hemisphere projections. 
TABLE 1

Summary of bedding measurements used in the fold test

\begin{tabular}{|c|c|c|c|c|c|}
\hline \multicolumn{3}{|c|}{ This study } & \multicolumn{3}{|c|}{ Seguin et al. (1987) } \\
\hline site & $\begin{array}{l}\mathrm{Az} \\
\left({ }^{\circ}\right)\end{array}$ & $\begin{array}{l}\text { Pl } \\
\left({ }^{\circ}\right)\end{array}$ & site & $\begin{array}{l}\mathrm{Az} \\
\left(^{\circ}\right)\end{array}$ & $\begin{array}{l}\text { Pl } \\
\left({ }^{\circ}\right)\end{array}$ \\
\hline $1-7$ & $351 \pm 4$ & $-02 \pm 3$ & $\begin{array}{l}\text { D8 } \\
\text { D9 }\end{array}$ & $\begin{array}{l}348 \\
351\end{array}$ & $\begin{array}{l}-06 \\
-09\end{array}$ \\
\hline $9-11$ & $325 \pm 5$ & $+01 \pm 2$ & $\begin{array}{l}\text { D5 } \\
\text { D7 }\end{array}$ & $\begin{array}{l}341 \\
344\end{array}$ & $\begin{array}{l}-02 \\
-14\end{array}$ \\
\hline $13-16$ & $332 \pm 5$ & $-03 \pm 4$ & D6 & 345 & -13 \\
\hline $17-19$ & $321 \pm 4$ & $+20 \pm 4$ & D4 & 342 & +19 \\
\hline
\end{tabular}

Explanation: $\mathrm{Az}$ and $\mathrm{Pl}$ are the azimuth and plunge of the downward noral to bedding (paleohorizontal) at each respective sampling localty; negative values for the plunge indicate overturned strata. For this study, Az and Pl are the average of the individual measurements plotted in Fig. 2, and the uncertainties correspond to the standard deviation of the measurements.

It is evident that the flows originally sampled (Fig. $2 \mathrm{a}-\mathrm{c}$ ) strike approximately east-northeast and all are very nearly vertical. However, those at sites $1-7$, and 13-16 are slightly overturned. The measurements from each locality are generally very consistent, while there is approximately a $20^{\circ}$ variation in strike between sites 17 and the others, as we indicated in our original study. The measurements at the new locality (Fig. 2d) reveal a similar northeast strike, but a local dip of only $70^{\circ}$, i.e. a difference of some $20-25^{\circ}$ relative to the other sites. Clearly, if stable high blocking temperature magnetizations similar to those found previously are present at the new sites, this difference in dip can contribute significantly to the fold test.

\section{New paleomagnetic data}

The Natural Remanent Magnetization (NRM) intensities for the volcanic samples from the new sites ranged from $10^{-1}$ to $10^{-2} \mathrm{~A} / \mathrm{m}$, similar to those reported for the previous collection by the authors. The NRM directions for these samples are generally grouped towards the southeast and upward, although a few directions from each site are southeasterly and downward. Samples from the new sites were demagnetized by stepwise heating and their directions were analyzed using the
Principal Component Analysis method of Kirschvink (1980). Typical demagnetization results are shown in Fig. 3.

The majority of samples from sites 17 and 18 that had well-grouped southeasterly and upward NRM directions revealed univectorial magnetizations with fairly discrete unblocking temperatures in the range from $600^{\circ}$ to $680^{\circ} \mathrm{C}$ (e.g., Fig. 3a, b). This behavior is similar to that observed in many of the volcanic samples from the first collection, and the high blocking temperature magnetization seen in Figs. $3 a, b$ will be referred to hereafter as the characteristic component. Additional samples from these sites revealed two components of magnetization (e.g., Fig. 3c). The component removed first by about $500^{\circ} \mathrm{C}$, is approximately aligned with the present-day field (PDF) direction, and is most likely of recent origin. The magnetization remaining after removal of the PDF component decays linearly to the origin between $600^{\circ}$ and $680^{\circ} \mathrm{C}$, revealing a direction and blocking temperatures similar to the characteristic component found in the univectorial samples from these sites. Directions determined for the characteristic components in all of the samples from sites 17 and 18, are shown in Fig. 4, together with the site means which are also listed in Table 2. It is noted that samples from the bottom, middle and top of each flow yielded similar characteristic directions. Overall, the demagnetization behavior of samples from sites 17 and 18 is very similar to that observed for the first collection of samples from the Dunn Point Formation. The characteristic high blocking temperature components found in the volcanics from these sites, as well as in those of the first study, are carried by hematite.

In contrast, only one of the samples from site 19 (DP19.A) displayed an approximately univectorial magnetization carried by hematite. More typically, samples from this site revealed multicomponent magnetizations such as shown in Fig. 5. A soft component of magnetization removed by about $350^{\circ} \mathrm{C}$ in all of the remaining samples is probably a PDF component, although its direction is not well defined. It could at first glance be argued that removal of a second component of magnetization in these samples is revealed by the more or less linear demagnetization trajectories 
a)

$$
\text { DPI7.A }
$$

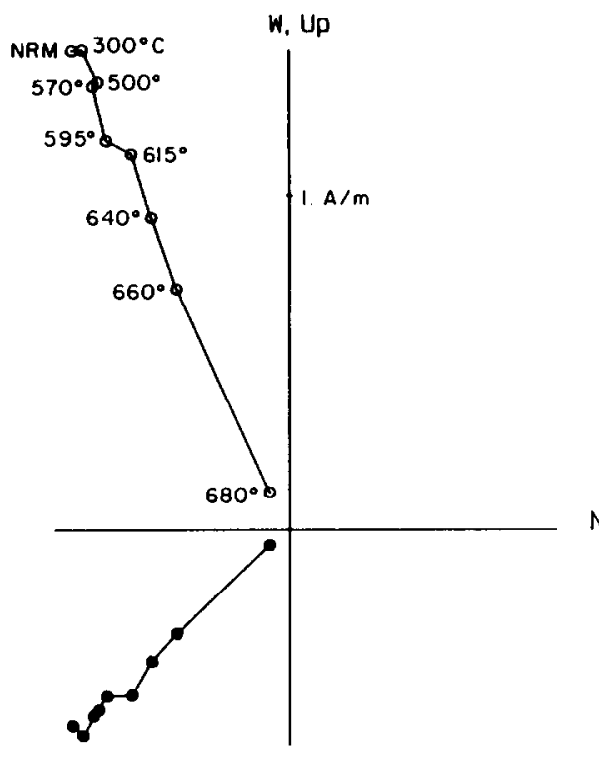

b) DPI8. B

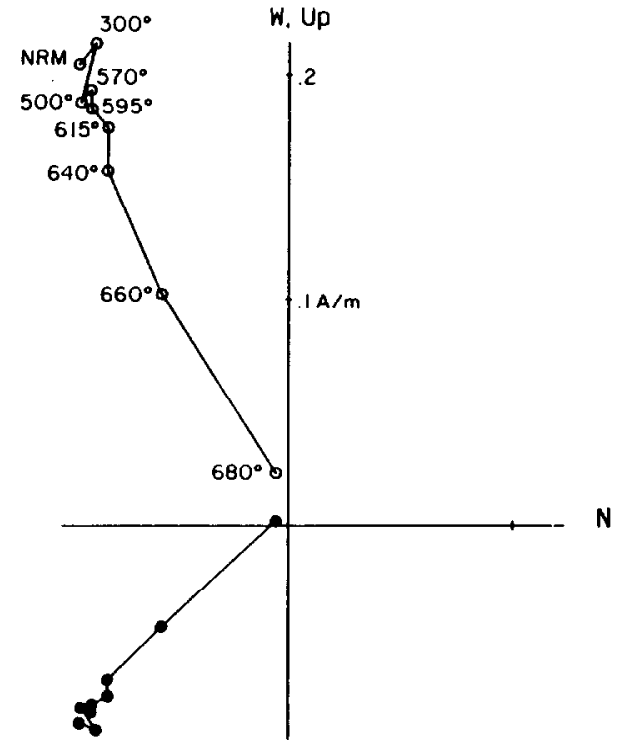

c)

DPI8.D

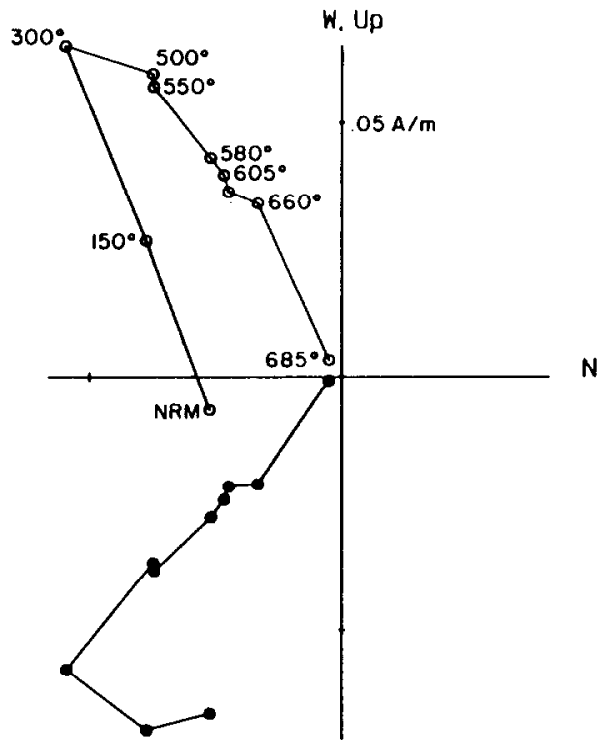

Fig. 3. Orthogonal vector diagrams showing stepwise thermal demagnetizations of samples from new sites 17 (a), and 18 (b,c), plotted in geographic (in situ) coordinates (Zijderveld, 1967). Open (closed) symbols represent projections of the vector endpoints onto the north-south vertical (horizontal) plane.

between $350^{\circ}$ and about $550^{\circ}$ that trend away from the origin (see Fig. 5). Directions for these "linear" segments are toward the south-southeast and shallow downward. During removal of the shallow component, and in subsequent thermal treatment, the directions for the magnetization remaining in these samples follow great-circle paths towards an east-southeast and upward direction, similar to the univectorial direction found for sample DP19.A (and sites 17, 18), indicating 
$\underline{\text { DP } 17}$

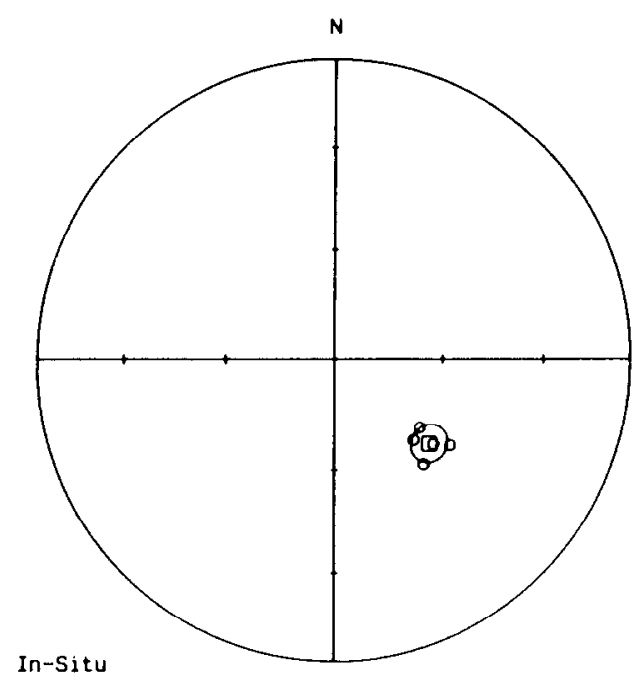

DP 18

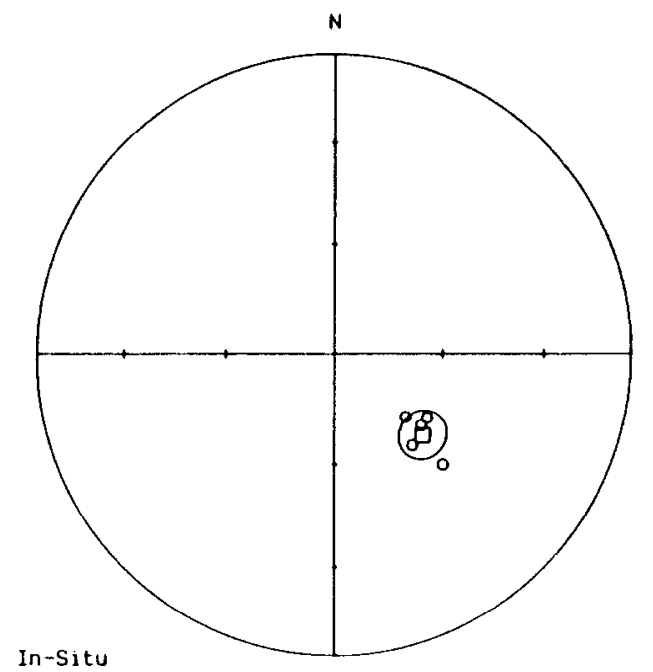

\section{DP 19}

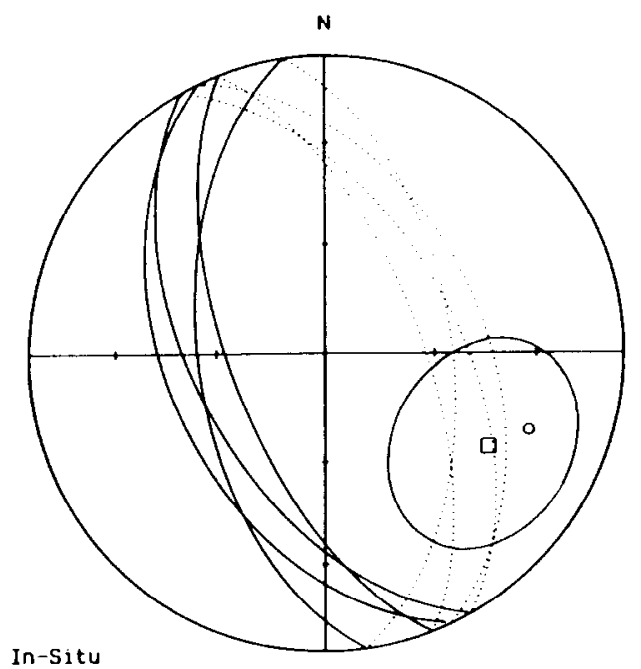

Fig. 4. Equal area plots showing sample directions (or sample great circles, c.g., site DP 19) and site means (squares), with their $95 \%$ confidence circles, for the characteristic magnetization at the three new sites in the Dunn Point volcanics. The great circles projections in the lower (upper) hemisphere are indicated by the solid (dotted) lines.

the presence of high blocking temperature components in all samples. Upon close inspection, however, it can be seen that the demagnetization trajectories are curved owing to overlapping blocking temperatures for the last two components of magnetization to be removed. Above $635^{\circ}$, unfortunately, some of these samples acquired large spurious magnetizations (Fig. 5). While this pre- vented identification of high blocking temperature components from the vector diagrams, best-fit planes to the sample great-circle trajectories have been calculated and these are combined with the direction for the univectorial magnetization in DP19.A to obtain a site mean for the characteristic component at this site (Fig. 4, and Table 2) following the method of Bailey and Halls (1984). 
TABLE 2

Summary of site mean paleomagnetic data

\begin{tabular}{|c|c|c|c|c|c|c|c|}
\hline \multirow[t]{2}{*}{ Site } & \multirow[t]{2}{*}{$n / n_{0}$} & \multicolumn{2}{|c|}{ Before TC } & \multicolumn{2}{|c|}{ After TC } & \multirow[t]{2}{*}{$k$} & \multirow[t]{2}{*}{$\alpha_{95}$} \\
\hline & & $D\left({ }^{\circ}\right)$ & $I\left(^{\circ}\right)$ & $D\left({ }^{\circ}\right)$ & $I\left(^{\circ}\right)$ & & \\
\hline 1 & $6 / 6$ & 159 & -31 & 9 & -55 & 151 & 5.5 \\
\hline 2 & $6 / 6$ & 174 & -27 & 346 & -61 & 77 & 7.7 \\
\hline 3 & $3 / 3$ & 172 & -20 & 348 & -68 & 113 & 11.7 \\
\hline 4 & $6 / 7$ & 173 & -25 & 347 & -63 & 321 & 3.7 \\
\hline 5 & $6 / 6$ & 169 & 21 & 356 & -67 & 224 & 4.5 \\
\hline 6 & $8 / 12$ & 169 & -29 & 354 & -59 & 63 & 7.0 \\
\hline 7 & $5 / 5$ & 179 & -24 & 335 & -63 & 75 & 8.9 \\
\hline 9 & $5 / 6$ & 147 & -31 & 322 & -60 & 45 & 11.5 \\
\hline 10 & $10 / 11$ & 151 & -47 & 319 & -44 & 53 & 6.7 \\
\hline 11 & $5 / 5$ & 144 & -37 & 326 & -54 & 111 & 7.3 \\
\hline 13 & $7 / 7$ & 138 & -25 & 357 & -59 & 136 & 5.2 \\
\hline $13^{\prime}$ & $9 / 9$ & 140 & -31 & 350 & -54 & 248 & 3.3 \\
\hline 14 & $5 / 6$ & 138 & -30 & 353 & -54 & 224 & 5.1 \\
\hline 15 & $6 / 6$ & 141 & -18 & 359 & -66 & 99 & 6.8 \\
\hline 16 & $6 / 6$ & 146 & -31 & 341 & -56 & 105 & 6.6 \\
\hline $16^{\prime}$ & $4 / 4$ & 141 & -25 & 352 & -60 & 223 & 6.2 \\
\hline 17 & $5 / 5$ & 131 & -55 & 331 & -54 & 229 & 5.1 \\
\hline 18 & $5 / 5$ & 132 & -57 & 329 & -52 & 134 & 6.6 \\
\hline 19 & $5 / 5$ & 120 & -37 & 4 & -65 & 33 & 27.4 \\
\hline Mean & $19 / 19$ & 152 & -33 & 344 & -60 & & 4.1 \\
\hline
\end{tabular}

Explanation: $n / n_{0}$ is the ratio of the samples used to calculate the mean to the number thermally demagnetized; TC is the simple tilt correction; $D$ and $I$ are the declination and inclination of the site mean direction. $k$ and $\alpha_{95}$ are the precision parameter and the radius of the circle of $95 \%$ confidence (Fisher, 1953). $k_{1}\left(k_{2}\right)$ is the precision parameter for the overall mean after (before) simple tilt correction, with $k_{1} / k_{2}=3.43$ for this study. The paleopole for the overall mean direction is located at $2^{\circ} \mathrm{N}, 130^{\circ} \mathrm{E}\left(\mathrm{d} p=4.7^{\circ}\right.$, $\mathrm{d} m=62^{\circ}$ ).

\section{DP $19.3 \mathrm{Ca}$}
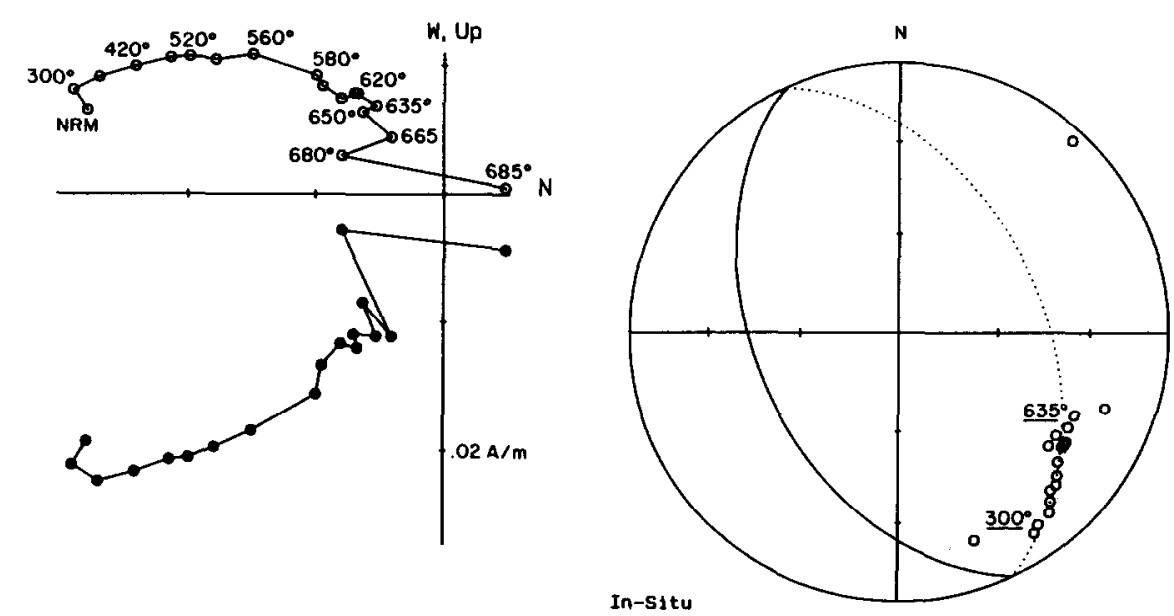

Fig. 5. Stepwise thermal demagnetization of a sample from site DP 19. The equal area plot shows the direction of magnetization after each successive heating step. The great circle shown in the equal area plot represents the (anchored) best-fit plane to the demagnetization trajectory between $300^{\circ}$ and $635^{\circ} \mathrm{C}$ (Kirschvink, 1980). 

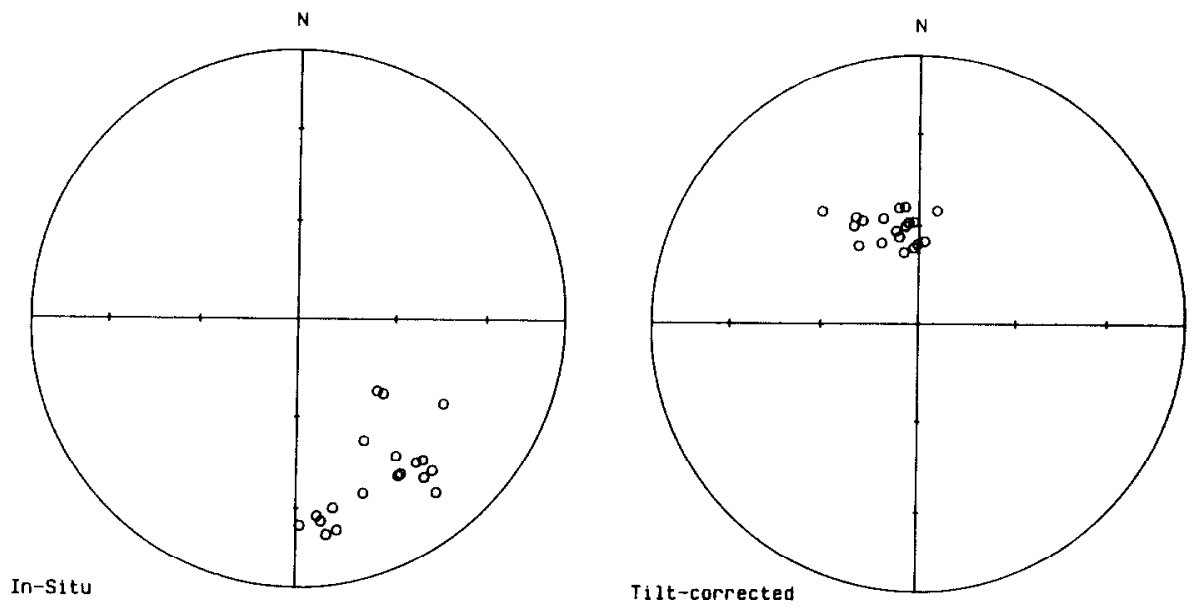

Fig. 6. Equal area plots of the site mean directions for the characteristic magnetization from all of the sites listed in Table 2, both in situ and after simple tilt correction.

Given the maximum unblocking temperatures inferred for the characteristic magnetization at this site, it is likely to be carried by hematite as well.

\section{Fold test}

Table 2 shows the site mean data for the characteristic components from all of the sites studied by us, including the previous sites 1-16 from the northern outcrop belt. The tilt corrected directions for the latter sites were recalculated using the (slightly) revised estimates of paleohorizontal reported in the present study (Table 1), and thus their directions in Table 2 differ slightly from those reported previously by Van der Voo and Johnson (1985).

The fold test combining all of the site mean directions from Table 2 , is illustrated by the equal area plots of the directions, before and after correction for simple tilt, shown in Fig. 6. Comparison of the in situ site means shows that the directions for the new sites have steeper inclinations and more easterly declinations than the others and, thus, they enhance the scatter of the in situ directions. The streaked distribution of the in situ site means, which results from the greater variation in their declinations than inclinations, is clearly non-Fisherian. Upon application of the correction for simple tilt of the volcanics (Fig. 6), however, the site mean directions converge toward a northerly and steeply upward direction, and their distribution becomes approximately Fisherian. The improved clustering of the site mean directions is evident from the increase in the precision parameter for the tilt corrected mean (Table 2 ), and the ratio of the precision parameters before and after correction for tilt indicate a significantly positive fold test at the $99 \%$ confidence level (McElhinny, 1964). This fold test thus reconfirms the prefolding age of the high blocking temperature magnetization carried by hematite in the Dunn Point volcanics. Its overall mean direction after correction for tilt is $D=344^{\circ}, I=$ $-60^{\circ}, k=68.6, \alpha_{95}=4.1^{\circ}$.

\section{Age of characteristic component}

The fold test for the high blocking temperature, or characteristic, component constrains its age to be pre-Middle Devonian. Although it is carried by hematite, the field evidence for early oxidation of the flows strongly suggests that the hematite probably formed at the time of their deposition. It is noted that scant evidence exists for similar steep directions of magnetization in Siluro-Devonian age rocks from Avalon (e.g., Kent and Van der Voo, 1989). However, there is no obvious mechanism for forming the hematite in the Dunn Point strata 
at that time, nor is there any evidence for oxidation of the overlying Early Silurian rocks in the Arisaig region. Thus, we infer an essentially primary (Late Ordovician-earliest Silurian) age for the characteristic magnetization in the Dunn Point Formation.

\section{Discussion}

The addition of data from the three new sites leaves few reasons to doubt the validity of the positive fold test or the pre-folding age for the characteristic component in the Dunn Point volcanics. The similar tilt corrected directions for the volcanic strata from different outcrop belts suggest that significant structural complexities beyond simple tilting of the strata are probably not present. Thus the simple tilt correction of the magnetic directions is appropriate.

The new study clearly corroborates the positive fold test for the high blocking temperature component reported by Van der Voo and Johnson (1985). The paleohorizontal measurements used in that earlier study have been refined by taking multiple sightings, which accounts for a slightly different set of mean directions. However, the overall means and precision parameters $(k)$, after tilt correction, are not significantly different from one another (Fig. 7).

On the other hand, the new results from this study do not confirm the outcome of the fold test for the high blocking temperature component performed by Seguin et al. (1987), nor their interpretation of a post-folding age for this component. Moreover, their inconclusive test is unlikely to be caused by undetected structural complexities. Instead, it is probably the result of greater scatter in magnetic directions as well as inaccuracies in their bedding attitude measurements. In addition, secular variation could be a significant contributor to the scatter if, as in our study, each site represents a single flow. However, this cannot be determined from their publication. Another possibility that cannot be ruled out is incomplete removal of overprint components in some of their samples. This could contribute to the increased within-site scatter of directions, as well as cause downward bias of the in situ directions toward the present-day

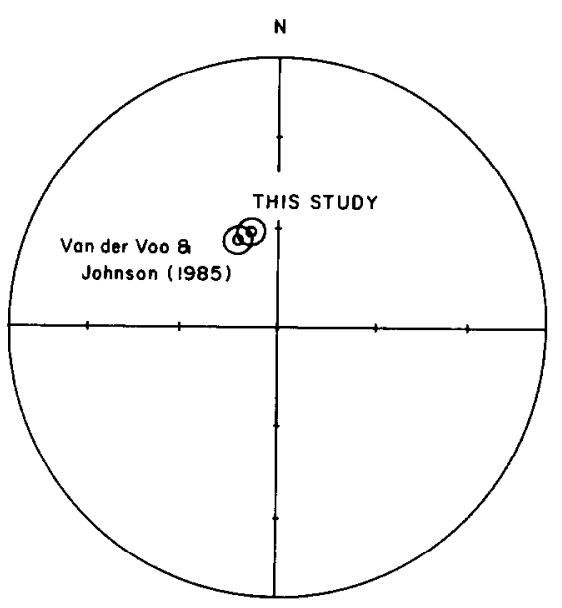

Fig. 7. Equal area plot of the overall mean direction, and $95 \%$ confidence circle, for the characteristic component in the Dunn Point volcanics determined in this study (see Table 2), compared with the direction reported previously by Van der Voo and Johnson (1985).

field direction. Based on our own experience, the thermal treatments described by Seguin et al. (1987) should have been adequate to isolate the characteristic component (with the exception of our site 19), but this may not be the case for samples treated with alternating fields. The net effect of all of these considerations is to increase the scatter and, hence, reduce the overall resolving power and significance of the fold test.

To assess the effect of perhaps erroneous paleohorizontal measurements on the outcome of their fold test, we recalculated the test using the $A$ component directions of Seguin et al. (1987) while substituting our measurements for paleohorizontal at sites in the northern and middle outcrop belts. This recalculation results in an improved grouping of site means after tilt correction $(k=30.7)$, but the fold test does not become significant at the 95\% confidence level. Thus we conclude that enhanced scatter due to some of the other effects mentioned in the preceeding paragraph must be invoked to explain the difference between our respective fold tests.

Regarding the other magnetic ( $B$ and $C$ ) components reported to be present in the volcanics (Seguin et al., 1987), we note that these are very 
poorly documented. Stable endpoint directions or linear demagnetization segments corresponding to the $B$ component, for example, are not convincingly demonstrated for any of the samples illustrated by those authors. Instead, many of the samples inferred to contain the $B$ component (Seguin et al., 1987) displayed great circle trends between the present day field (PDF) direction and the expected direction for the characteristic component during thermal demagnetization. Thus we would argue that such trends probably result from the simultaneous removal of a characteristic component and a large PDF overprint having overlapping blocking temperatures, rather than from the presence of an intermediate $(B)$ component. While this cannot be tested with the available information, we suggest that the $B$ components be regarded as composite and without tectonic significance (see also our interpretation of Fig. 5).

The $C$ component of Seguin et al. (1987) is equally poorly documented and has not been interpreted as to its possible origin by Seguin and co-workers. We have not observed any indication of such a component in our samples; we interpret the $C$ component as an artifact.

In summary, we argue that the characteristic component ( $A$ component of Seguin and coworkers) is the only reliable component of magnetization identified in the Dunn Point Formation. This component is pre-folding in age, not Jurassic, and appears to represent the Late Ordovicianearliest Silurian geomagnetic field in Avalon.

\section{Tectonic implications}

The mean direction for the characteristic magnetization in the Dunn Point Formation from this study yields a new paleopole located at $2^{\circ} \mathrm{N}$, $130^{\circ} \mathrm{E}$ and a Late Ordovician-earliest Silurian paleolatitude for Avalon of $41^{\circ} \mathrm{S}$. Paleolatitudes predicted for the present location of our sampling area from North American Late Ordovician paleopoles range from $12^{\circ} \mathrm{S}$ to $24^{\circ} \mathrm{S}$ (Miller and Kent, 1989). Thus, a latitudinal separation and subsequent relative displacement of at least 1700 $\mathrm{km}$ is indicated between Avalon and North America in the Late Ordovician-earliest Silurian.
On the other hand, the paleolatitude indicated by the new result for the Dunn Point is clearly within the range occupied by Gondwana and the Armorican blocks (e.g., Van der Voo, 1988), and it therefore does not contradict the interpretation that Avalon was still together with these blocks at this time. With reference to the Middle/Late Ordovician and middle Silurian reconstructions of Van der Voo (1988), a position for Avalon near northwestern South America or northwest Africa is consistent with the paleolatitude indicated by the Dunn Point result.

\section{Conclusions}

Paleomagnetic investigation of inclined volcanic flows from the middle outcrop belt of the Dunn Point Formation reveals a characteristic component of magnetization, carried by hematite, similar to that reported in previous studies of this unit. A new fold test for this component, combining paleomagnetic and structural data from the present study with paleomagnetic data for the exclusively vertically dipping flows studied previously by the authors (Van der Voo and Johnson, 1985), is significantly positive. This evidence reconfirms the pre-folding age of the characteristic component. We infer a Iate-Ordovician-earliest Silurian time of acquisition of the characteristic magnetization based on field evidence for subareal deposition and early oxidation of the flows.

The results of this study do not corroborate the inconclusive fold test, or the post-folding age, reported for the hematite component in the Dunn Point Formation by Seguin et al. (1987). We attribute the difference between the Dunn Point studies to inaccuracies in their structural and paleomagnetic measurements.

The overall mean direction for the characteristic component from this study $\left(D=344^{\circ}, I=\right.$ $-60^{\circ}$ ), corresponds to a paleolatitude for Avalon of $41^{\circ} \mathrm{S}$. The latter indicates a latitudinal separation between Avalon and North America in the Late Ordovician-early Silurian of at least 1700 $\mathrm{km}$. The Dunn Point result supports previous reconstructions that show Avalon together with the continental blocks of Hercynian Europe and northwestern Gondwana. 


\section{Acknowledgements}

This work was supported by the Division of Earth Sciences, the National Science Foundation, grant EAR 86-12469.

\section{References}

Bailey, R.C. and Halls, H.C., 1984. Estimate of confidence in paleomagnetic directions derived from mixed remagnetization-circle and direct observational data. J. Geophys., 54: 174-182.

Benson, D.G., 1974. Geology of the Antigonish Highlands, Nova Scotia. Geol. Surv. Can. Mem., 376: 92 pp.

Boucot, A.J., Dewey, J.F., Dineley, D.L., Fletcher, R., Fyson, W.K., Griffin, J.G., Hickox, C.F., McKerrow, W.S. and Ziegler, A.M., 1974. Geology of the Arisaig Area, Antigonish County, Nova Scotia. Geol. Soc. Am., Spec. Pap., 139: $191 \mathrm{pp}$.

Cocks, L.R.M. and Fortey, R.A., 1982. Faunal evidence for oceanic separation in the Paleozoic of Britain. J. Geol. Soc. London, 139: 465-478.

Dunn, W.J. and Elmore, R.D., 1985. Paleomagnetic and petrographic investigation of the Taum Sauk Limestone, southeast Missouri, J. Geophys. Res., 90: 11469-11483.

Fang, W., Van der Voo, R. and Johnson, R.J.E., 1986. Eocambrian paleomagnetism of the Boston Basin: evidence for a displaced terrane. Geophys. Res. Lett., 13: 1450-1453.

Fisher, R.A., 1953. Dispersion on a sphere. Proc. R. Soc. London, Ser. A, 217: 295-305.

Johnson, R.J.E. and Van der Voo, R., 1985. Middle Cambrian paleomagnetism of the Avalon terrane in Cape Breton Island, Nova Scotia. Tectonics, 4: 629-651.

Johnson, R.J.E. and Van der Voo, R., 1986. Paleomagnetism of the Late Precambrian Fourchu, Cape Breton Island, Nova Scotia. Can. J. Earth Sci., 23: 1673-1685.

Keppie, J.D., Dostal, J. and Zentilli, M., 1978. Petrology of the Early Silurian Dunn Point and McGillivray Brook formations, Arisaig, Nova Scotia. Nova Scotia Dep. Mines and Energy, Pap. 78-5: 20 pp.

Kent, D.V. and Van der Voo, R., 1990. Paleozoic paleogeography from paleomagnetism of the Atlantic-bordering continents. In: C.R. Scotese and W.S. McKerrow (Editors), Paleozoic Paleogeography and Biogeography. Geol. Soc. London Mem., 12: 49-56.
Kirschvink, J.L., 1980. The least squares line and plane and the analysis of paleomagnetic data. Geophys. J. R. Astron. Soc., 62: 699-718.

Lynnes, C.S. and Van der Voo, R., 1984. Paleomagnetism of the Cambro-Ordovician McClure Mountain alkalic complex, Colorado. Earth Planet. Sci. Lett., 71: 163-172.

Miller, J.D. and Kent. D.V., 1989. Paleomagnetism of the Upper Ordovician Juniata Formation of the central Appalachians revisited again. J. Geophys. Res., 94: 1843-1850.

McElhinny, M.W., 1964. Statistical significance of the fold test in paleomagnetism. Geophys. J.R. Astron. Soc., 8: 338-340.

Pickerill, R.K. and Hurst, J.M., 1983. Sedimentary facies, depositional environments, and faunal associations of the lower Llandovery (Silurian) Beechill Cove Formation, Arisaig, Nova Scotia. Can. J. Earth Sci., 20: 1761-1779.

Rast, N. and Skehan, J.W., 1983. Evolution of the Avalonian Plate. Tectonophysics, 100: 257-286.

Seguin, M.K., Rao, K.V. and Deutsch, E.R., 1987. Paleomagnetism and rock magnetism of Early Silurian Dunn Point volcanics, Avalon Zone, Nova Scotia. Phys. Earth Planet. Inter., 46: 369-380.

Van der Voo, R., 1988. Paleozoic paleogeography of North America, Gondwana, and intervening displaced terranes: comparisons of paleomagnetism with paleoclimatology and biogeographical patterns. Geol. Soc. Am. Bull., 100: 311324.

Van der Voo, R. and Johnson, R.J.E., 1985. Paleomagnetism of the Dunn Point Formation (Nova Scotia): high paleolatitudes for the Avalon terrane in the Late Ordovician. Geophys. Res. Lett., 12: 337-340.

Watts, D.R., Van der Voo, R. and Reeve, S.C., 1980. Cambrian paleomagnetism of the Llano uplift, Texas, J. Geophys. Res., 85: 5316-5330.

Weisse, P.A., Haggerty, S.E. and Brown, L.L., 1985. Paleomagnetism and magnetic mineralogy of the Nahant Gabbro and tonalite, eastern Massachusetts. Can. J. Earth Sci., 16: 792-807.

Wilson, J.T., 1966. Did the Atlantic close and then reopen? Nature, 211: 676-681.

Zijderveld, J.D.A., 1967. AC demagnetization of rocks: analysis of results.In: D.W. Collinson, K.M. Creer and S.K. Runcorn (Editors), Methods in Paleomagnetism. Elsevier, Amsterdam, pp. 254-286. 